\title{
Video Article \\ Promoter Capture Hi-C: High-resolution, Genome-wide Profiling of Promoter Interactions
}

\author{
Stefan Schoenfelder ${ }^{*}$, Biola-Maria Javierre ${ }^{1,2}$, Mayra Furlan-Magaril ${ }^{1,3}$, Steven W. Wingett ${ }^{1,4}$, Peter Fraser ${ }^{1,5}$ \\ ${ }^{1}$ Nuclear Dynamics Programme, The Babraham Institute, Babraham Research Campus \\ ${ }^{2}$ IJC Building, Campus ICO-Germans Trias i Pujol, Josep Carreras Leukemia Research Institute \\ ${ }^{3}$ Departamento de Genética Molecular, Instituto de Fisiología Celular, Universidad Nacional Autónoma de México \\ ${ }^{4}$ Bioinformatics Group, The Babraham Institute, Babraham Research Campus \\ ${ }^{5}$ Department of Biological Science, Florida State University \\ *These authors contributed equally
}

Correspondence to: Stefan Schoenfelder at stefan.schoenfelder@babraham.ac.uk, Biola-Maria Javierre at bmjavierre@carrerasresearch.org, Peter Fraser at peter.fraser@babraham.ac.uk

URL: https://www.jove.com/video/57320

DOI: doi: $10.3791 / 57320$

Keywords: Genetics, Issue 136, 3D genome organization, promoters, enhancers, long-range interactions, Hi-C, cis-regulatory elements, genomewide association study (GWAS), non-coding disease variants, chromatin loops, CHiCAGO, HiCUP

Date Published: 6/28/2018

Citation: Schoenfelder, S., Javierre, B.M., Furlan-Magaril, M., Wingett, S.W., Fraser, P. Promoter Capture Hi-C: High-resolution, Genome-wide Profiling of Promoter Interactions. J. Vis. Exp. (136), e57320, doi:10.3791/57320 (2018).

\section{Abstract}

The three-dimensional organization of the genome is linked to its function. For example, regulatory elements such as transcriptional enhancers control the spatio-temporal expression of their target genes through physical contact, often bridging considerable (in some cases hundreds of kilobases) genomic distances and bypassing nearby genes. The human genome harbors an estimated one million enhancers, the vast majority of which have unknown gene targets. Assigning distal regulatory regions to their target genes is thus crucial to understand gene expression control. We developed Promoter Capture Hi-C (PCHi-C) to enable the genome-wide detection of distal promoter-interacting regions (PIRs), for all promoters in a single experiment. In $\mathrm{PCHi}-\mathrm{C}$, highly complex Hi-C libraries are specifically enriched for promoter sequences through in-solution hybrid selection with thousands of biotinylated RNA baits complementary to the ends of all promoter-containing restriction fragments. The aim is to then pull-down promoter sequences and their frequent interaction partners such as enhancers and other potential regulatory elements. After high-throughput paired-end sequencing, a statistical test is applied to each promoter-ligated restriction fragment to identify significant PIRs at the restriction fragment level. We have used $\mathrm{PCHi}-\mathrm{C}$ to generate an atlas of long-range promoter interactions in dozens of human and mouse cell types. These promoter interactome maps have contributed to a greater understanding of mammalian gene expression control by assigning putative regulatory regions to their target genes and revealing preferential spatial promoter-promoter interaction networks. This information also has high relevance to understanding human genetic disease and the identification of potential disease genes, by linking non-coding diseaseassociated sequence variants in or near control sequences to their target genes.

\section{Video Link}

The video component of this article can be found at https://www.jove.com/video/57320/

\section{Introduction}

Accumulating evidence suggests that the three-dimensional organization of the genome plays an important functional role in a range of nuclear processes, including gene activation ${ }^{1,2,3}$, repression ${ }^{4,5,6,7,8}$, recombination ${ }^{9,10}$, DNA repair ${ }^{11}$, DNA replication ${ }^{12,13}$, and cellular senescence ${ }^{14}$. Distant enhancers are found in close spatial proximity to the promoters they regulate ${ }^{15,16,17}$, which is essential for proper spatio-temporal gene expression control. Enhancer deletions show that distal enhancers are essential for target gene transcription ${ }^{18,19,20,21,22}$, and 'forced chromatin looping' demonstrates that engineered tethering between an enhancer and its target promoter in the Hbb locus is sufficient to drive transcriptional activation $^{23}$. Further, genome rearrangements that bring genes under the control of ectopic enhancers can result in inappropriate gene activation and disease $e^{24,25,26}$. Together, these examples illustrate that promoter-enhancer interactions are essential for gene control and require tight regulation to ensure appropriate gene expression. The human and mouse genomes are each estimated to harbor around one million enhancers. For the vast majority of these enhancers, target genes are unknown, and the 'rules of engagement' between promoters and enhancers are poorly understood. Assigning transcriptional enhancers to their target genes thus remains a major challenge in deciphering mammalian gene expression control.

Our understanding of three-dimensional genome architecture has been revolutionized by the introduction of $3 \mathrm{C}^{27}$ (chromosome conformation capture) and its variants ${ }^{28,29,30,31}$. The most powerful of these techniques, Hi-C (high throughput chromosome conformation capture) is designed to identify the entire ensemble of chromosomal interactions within a cell population. Hi-C libraries, typically generated from millions of cells, are highly complex with an estimated $10^{11}$ independent ligation products between $\sim 4 \mathrm{~kb}$ fragments in the human genome ${ }^{32}$. As a consequence, reliable and reproducible identification of interactions between individual restriction fragments (such as those containing a promoter or enhancer) 
from $\mathrm{Hi}-\mathrm{C}$ data is not feasible unless $\mathrm{Hi}-\mathrm{C}$ libraries are subjected to ultra-deep sequencing, which is not an economically viable solution for laboratories preparing $\mathrm{Hi}-\mathrm{C}$ libraries routinely. To circumvent this shortcoming, we developed Promoter Capture Hi-C to specifically enrich promoter-containing ligation products from Hi-C libraries. We focused on promoters for two reasons. First, promoter-enhancer contacts have been shown to be crucial for proper gene expression levels in numerous studies (see references above), and second, as promoters are largely invariant between cell types, the same capture bait system can be used to interrogate the regulatory circuitry across multiple cell types and conditions. Our approach relies on in-solution hybridization of Hi-C libraries with tens of thousands of biotinylated RNA 120mers complementary to promoter-containing $\mathrm{Hi}-\mathrm{C}$ ligation products and subsequent capture on streptavidin-coated magnetic beads. This results in PCHi-C libraries with much reduced complexity compared to the original $\mathrm{Hi}-\mathrm{C}$ library, focusing only on the identification of fragments that are ligated to promoters at significantly high frequencies.

We have used $\mathrm{PCHi}-\mathrm{C}$ in a number of human and mouse cell types to contribute to a better understanding of gene expression control by uncovering long-range distal promoter interacting regions with putative regulatory function, as well as non-random promoter-promoter contacts in the three-dimensional space of the nucleus. The studies have mapped hundreds of thousands of promoter-enhancer contacts across numerous cell types $^{33,34,35,36,37,38,39}$, identified Polycomb Repressive Complex-mediated spatial genome organization in mouse embryonic stem cells ${ }^{7}$, demonstrated large-scale rewiring of promoter interactomes during cellular differentiation ${ }^{37,38,39}$, and linked non-coding disease-associated sequence variants to gene promoters ${ }^{35}$.

$\mathrm{PCHi}-\mathrm{C}$ is an ideally suited method to map the genome-wide ensemble of DNA sequences interacting with promoters. Related approaches, such as Capture Hi-C of continuous genomic regions (see Discussion) are the method of choice to obtain high-resolution interaction profiles for selected genomic regions. PCHi-C and Capture $\mathrm{Hi}-\mathrm{C}$ are extremely similar from an experimental point of view (the only difference is the choice of capture system), so that the advice and guidelines we provide are applicable to both approaches. Here, we present a detailed description of $\mathrm{PCHi}-\mathrm{C}$. We outline the rationale and design of a $\mathrm{PCHi}-\mathrm{C}$ experiment, provide a step-by-step $\mathrm{PCH}-\mathrm{C}$ library generation protocol, and illustrate how the quality of PCHi-C libraries can be monitored at various steps in the protocol to yield high-quality data.

\section{Formaldehyde Fixation}

1. Cell preparation: Start with a minimum of $2 \times 10^{7}$ cells per experiment.

1. For cells grown in culture, resuspend the cells in culture medium. For ex vivo cells, resuspend in 1x Dulbecco's Modified Eagle Medium (DMEM), supplemented with $10 \%$ (vol/vol) fetal bovine serum (FBS).

2. For adherent cells, remove culture medium and add $30.625 \mathrm{~mL}$ of fresh medium with $10 \%$ (vol/vol) FBS at room temperature (RT; $20-$ $\left.25^{\circ} \mathrm{C}\right)$.

3. For suspension cells, collect and centrifuge cells at $400 \times \mathrm{g}$ and $20^{\circ} \mathrm{C}$ for $3 \mathrm{~min}$. Remove supernatant and re-suspend cell pellet in $30.625 \mathrm{~mL}$ of medium with $10 \%$ (vol/vol) FBS at RT.

4. For solid tissues, use trypsin $(0.05 \%$ to $2.5 \%$ final concentration, depending on cell type) or dounce homogenizing to obtain a single cell suspension. After this additional step, treat cells like suspension cells.

2. Add $4.375 \mathrm{~mL}$ of $16 \%$ methanol-free paraformaldehyde (open ampoule just prior to use) to a final concentration of $2 \%$ (vol/vol). Fix for $10 \mathrm{~min}$ at RT with gentle mixing on a rocker.

CAUTION: Paraformaldehyde is a hazardous chemical. Follow the appropriate health and safety regulations.

3. Quench reaction by adding $5 \mathrm{~mL}$ of freshly-prepared $1 \mathrm{M}$ ice-cold glycine. Mix for $5 \mathrm{~min}$ with gentle rocking at RT, and then incubate on ice for 15 min with occasional inverting.

4. Wash and collect fixed cells.

1. For adherent cells, remove supernatant, add $10 \mathrm{~mL}$ of ice-cold $1 \times \mathrm{PBS} \mathrm{pH} 7.4$ on the plate wall and remove it. Add $1 \mathrm{~mL}$ of ice-cold $1 \mathrm{x}$ PBS pH 7.4, collect cells using a cell scraper and transfer into a $50 \mathrm{~mL}$ tube. Repeat twice to collect as many cells as possible. Add icecold PBS up to $50 \mathrm{~mL}$ final volume.

2. For suspension cells, centrifuge cells at $760 \times \mathrm{g}$ and $4{ }^{\circ} \mathrm{C}$ for $5 \mathrm{~min}$, remove supernatant, and re-suspend cell pellet in $50 \mathrm{~mL}$ of ice-cold PBS pH 7.4.

5. Centrifuge cells at $400 \times g$ and $4{ }^{\circ} \mathrm{C}$ for $10 \mathrm{~min}$ and carefully remove supernatant. The cell pellet can be snap frozen in liquid nitrogen and subsequently stored at $-80^{\circ} \mathrm{C}$ for several months.

\section{Cell Lysis}

1. Re-suspend cell pellet in $50 \mathrm{~mL}$ of freshly-prepared ice-cold lysis buffer ( $10 \mathrm{mM} \mathrm{Tris-HCl} \mathrm{pH} 8,0.2 \%$ (vol/vol) lgepal CA-630, $10 \mathrm{mM} \mathrm{NaCl}$, and one tablet protease inhibitor cocktail) and mix. Incubate on ice for $30 \mathrm{~min}$, mix occasionally by inverting. Centrifuge the nuclei at $760 \times \mathrm{g}$ and $4{ }^{\circ} \mathrm{C}$ for 5 min and remove supernatant.

\section{Hindlll Digestion}

1. Wash cell nuclei with $1.25 x$ restriction buffer 2 . Re-suspend cell pellet in $1 \mathrm{~mL}$ of ice-cold $1.25 \mathrm{x}$ restriction buffer 2 and transfer into a $1.5 \mathrm{~mL}$ tube. Spin the nuclei at $760 \mathrm{xg}$ and $4{ }^{\circ} \mathrm{C}$ for $5 \mathrm{~min}$ and remove supernatant.

2. Re-suspend cell pellet in $1790 \mu \mathrm{L}$ of $1.25 \mathrm{x}$ restriction buffer 2 . Make 5 aliquots, each containing $5-10$ million cells in $358 \mu \mathrm{L}$ of $1.25 \mathrm{x}$ restriction buffer 2 .

3. Add $11 \mu \mathrm{L}$ of $10 \%$ (wt/vol) SDS per aliquot and shake at 950 revolutions per min (rpm) for $30 \mathrm{~min}$ at $37^{\circ} \mathrm{C}$ in a thermomixer. If cell clumps appear, dissociate by pipetting, avoiding bubbles. 
4. Add $75 \mu \mathrm{L}$ of $10 \%$ Triton $\mathrm{X}-100$ (vol/vol) per aliquot and shake at $950 \mathrm{rpm}$ and $37^{\circ} \mathrm{C}$ for $15 \mathrm{~min}$ in a thermomixer. If cell clumps appear, dissociate by pipetting, avoiding bubbles.

5. Add $12 \mu \mathrm{L}$ of $100 \mathrm{U} / \mu \mathrm{L}$ HindIII $100\left(1,200\right.$ units in total) per aliquot and incubate at $37^{\circ} \mathrm{C}$ overnight (O/N) while shaking at $950 \mathrm{rpm}$ in a thermomixer.

1. For the digestion control, transfer $25 \mu \mathrm{L}$ of sample ( $5 \mu \mathrm{L}$ from each aliquot) in a new tube before adding the enzyme (undigested control) and repeat the same procedure after adding the enzyme (digested control). Incubate both tubes in the same manner as the HiC library.

6. On the following morning, add $5 \mu \mathrm{L}$ of $100 \mathrm{U} / \mu \mathrm{L}$ HindIII (500 units in total) per aliquot and incubate at $37^{\circ} \mathrm{C}$ for $2 \mathrm{~h}$ while shaking at $950 \mathrm{rpm}$ in a thermomixer.

7. Digestion control: for the digested and undigested controls (see 3.5.1), perform crosslink reversal (step 6), Phenol:Chloroform extraction, and DNA precipitation (step 7).

1. Design a pair of primers that span a HindlII site. In the same region, design another pair of primers that don't span a Hindlll site. Design primers for quantitative PCR (Q-PCR) using Primer3 (http://bioinfo.ut.ee/primer3-0.4.0/) and the following parameters:

Primer size: Optimal 20 (Min.: 18, Max.: 27); Primer Tm: Optimal 60 (Min.: 57, Max.: 63);Primer CG\% content: Min.: 20, Max.: 80; Amplicon size: RT-PCR $\sim 100$ bp (for conventional PCR 300 bp); Mispriming library: human (human primers) or rodent and simple (mouse primers).

2. Perform Q-PCR to obtain 4 mean Cts (threshold cycle): $\mathrm{Ct}[\mathrm{D} ; \mathrm{H}]$, obtained from the digested sample [D] with the pair of primers that span a HindlII site [H]; Ct[D;-], obtained from the digested sample [D] with the pair of primers that don't span a HindIII site [-]; Ct[U;H], obtained from the undigested sample [U] with the pair of primers that span a HindllI site; Ct[U;-], obtained from the undigested sample [U] with the pair of primers that don't span a HindlII site [-]. Calculate the percentage of digestion as: \% digestion $=100-100 / 2^{(\mathrm{Ct}[\mathrm{D}, \mathrm{H}]-}$ Ct[D,-]) - (Ct[U,H]-Ct[U,-])

\section{Biotinylation of Restriction Fragment Overhangs}

1. Prepare biotinylation master mix: $30.6 \mu \mathrm{L}$ of $10 x$ restriction buffer $2,10.2 \mu \mathrm{L}$ of $\mathrm{H}_{2} \mathrm{O}$ (molecular biology grade), $7.65 \mu \mathrm{L}$ of $10 \mathrm{mM}$ dCTP, 7.65 $\mu \mathrm{L}$ of $10 \mathrm{mM}$ dGTP, $7.65 \mu \mathrm{L}$ of $10 \mathrm{mM}$ dTTP, $191.25 \mu \mathrm{L}$ of $0.4 \mathrm{mM}$ biotin-14-dATP, and $51 \mu \mathrm{L}$ of 5,000 U/mL DNA polymerase I large (Klenow) fragment.

2. Add $60 \mu \mathrm{L}$ of biotinylation master mix per aliquot, mix, and incubate at $37^{\circ} \mathrm{C}$ for $1 \mathrm{~h}$ shaking at $700 \mathrm{rpm}$ (thermomixer) for $5 \mathrm{~s}$, every $30 \mathrm{~s}$. After $1 \mathrm{~h}$, place aliquots on ice.

\section{In-nucleus Ligation}

1. Prepare ligation master mix: $510 \mu \mathrm{L}$ of $10 x$ T4 DNA ligase buffer, $51 \mu \mathrm{L}$ of $10 \mathrm{mg} / \mathrm{mL}$ Bovine Serum Albumin (100x BSA), $1754.4 \mu \mathrm{L}$ of water (molecular biology grade), and $127.5 \mu \mathrm{L}$ of $1 \mathrm{U} / \mu \mathrm{L}$ T4 DNA ligase (see Table of Materials).

2. Add $479 \mu \mathrm{L}$ of ligation master mix per aliquot mix and incubate at $16{ }^{\circ} \mathrm{C}$ for $4 \mathrm{~h}$ shaking at $700 \mathrm{rpm}$ for $5 \mathrm{~s}$ every 2 min in a thermomixer.

3. Incubate $30 \mathrm{~min}$ at RT.

\section{Crosslink Reversal}

1. Combine all aliquots in a $50 \mathrm{~mL}$ centrifuge tube (suitable for high-speed centrifugation).

2. Add $62.5 \mu \mathrm{L}$ of $10 \mathrm{mg} / \mathrm{mL}$ RNase $\mathrm{A}$, mix, and incubate for $30 \mathrm{~min}$ at $37^{\circ} \mathrm{C}$.

3. Add $300 \mu \mathrm{L}$ of $10 \mathrm{mg} / \mathrm{mL}$ Proteinase $\mathrm{K}$, mix, and incubate for $30 \mathrm{~min}$ at $37^{\circ} \mathrm{C}$.

4. Incubate reaction $\mathrm{O} / \mathrm{N}$ (or at least $4 \mathrm{~h}$ ) at $65^{\circ} \mathrm{C}$. On the following morning, add $300 \mu \mathrm{L}$ of $10 \mathrm{mg} / \mathrm{mL}$ Proteinase $\mathrm{K}$, mix, and incubate for $1 \mathrm{~h}$ at $65^{\circ} \mathrm{C}$.

\section{DNA Purification}

1. Add $4337.5 \mu \mathrm{L}$ of TLE buffer (10 mM Tris-HCl pH 8.0; $0.1 \mathrm{mM}$ EDTA pH 8.0) and mix.

2. Add 1 volume $(10 \mathrm{~mL}$ ) phenol $\mathrm{pH} 8.0$, vortex for $10 \mathrm{~s}$, and centrifuge at RT and $20,000 \times \mathrm{g}$ for $3 \mathrm{~min}$. Transfer $9 \mathrm{~mL}$ of the upper (aqueous) phase to a new $50 \mathrm{~mL}$ tube. CAUTION: Phenol is a hazardous chemical . Follow the appropriate health and safety regulations.

3. Add $2 \mathrm{~mL}$ of TLE buffer to the remaining aqueous phase, vortex for $10 \mathrm{~s}$ and centrifuge at RT and $20,000 \times \mathrm{g}$ for $3 \mathrm{~min}$. Transfer $2.5 \mathrm{~mL}$ of the aqueous phase into the new tube from step 7.2, making the final volume $11.5 \mathrm{~mL}$. Discard tube containing the lower (organic) phase.

4. Add 1 volume $(11.5 \mathrm{~mL})$ of phenol:chloroform:isoamyl alcohol $(25: 24: 1)$, vortex for $10 \mathrm{~s}$, and centrifuge at RT and 20,000 $\times \mathrm{g}$ for $3 \mathrm{~min}$. Transfer $11 \mathrm{~mL}$ of the upper (aqueous) phase to a new $50 \mathrm{~mL}$ tube. Repeat step 7.3. The total sample volume will now be $13.5 \mathrm{~mL}$.

5. Add $1.35 \mathrm{~mL}$ of $3 \mathrm{M}$ sodium acetate $\mathrm{pH} 5.2$ and $33.75 \mathrm{~mL}$ of ice cold $100 \%$ ethanol, mix, and incubate at $-80{ }^{\circ} \mathrm{C}$ for $45 \mathrm{~min}$, or alternatively overnight at $-20^{\circ} \mathrm{C}$.

6. Centrifuge at $4{ }^{\circ} \mathrm{C}$ and $20,000 \times g$ for $10 \mathrm{~min}$, remove supernatant, re-suspend pellet in $1 \mathrm{~mL}$ of freshly-prepared $70 \%$ (vol/vol) ethanol, and transfer to a new tube.

7. Centrifuge at $4{ }^{\circ} \mathrm{C}$ and at full speed for $3 \mathrm{~min}$ in a benchtop centrifuge, then remove supernatant.

8. Re-suspend pellet in $1 \mathrm{~mL}$ of ice cold $70 \%$ (vol/vol) ethanol and repeat step 7.7. Dry the pellet at $37^{\circ} \mathrm{C}$ for $10 \mathrm{~min}$ and re-suspend in $650 \mu \mathrm{L}$ of TLE buffer. Determine the DNA yield by using a fluorescence-based assay to quantify double-stranded DNA.

NOTE: The protocol can be paused here by snap freezing and storing the sample at $-80^{\circ} \mathrm{C}$ for several months or at $-20^{\circ} \mathrm{C}$ for a shorter period of time. 


\section{Quality Controls}

1. Monitor library integrity and ligation by DNA electrophoresis. Run $200 \mathrm{ng}$ of library on a $0.8 \%$ agarose/1x TBE gel. The DNA should run as a band over $10 \mathrm{~kb}$.

2. Detect known cell-type invariant short- and long-range interactions by conventional PCR. Use 100 ng of template DNA per PCR reaction. Design the PCR primers close and towards the restriction sites following the instructions above (see 3.7.1). Primer sequences for quality control of mouse and human $\mathrm{Hi}-\mathrm{C}$ libraries are listed in Table 1.

3. Fill-in and ligation control: Cut out the gel bands containing the amplicons from control 8.2, gel-extract DNA, and use the DNA as template for 4 individual PCR reactions with identical primer combinations.

1. Purify amplicons using a PCR purification kit and quantify the DNA concentration.

2. Prepare four digestion reactions (HindlII [a], Nhel [b], HindlII + Nhel [c] and no enzyme [d]) for each amplicon in a final volume of 15 $\mu \mathrm{L}$ : $500 \mathrm{ng}$ of amplicon, $1.5 \mu \mathrm{L}$ of $10 \mathrm{x}$ restriction buffer $2.1,0.15 \mu \mathrm{L}$ of $10 \mathrm{mg} / \mathrm{mL}$ Bovine Serum Albumin (100x BSA), and $0.1 \mu \mathrm{L}(10$ units) of enzyme (HindIII [a], Nhel [b], HindIII + Nhel [c] or water [d]).

3. Digest for $1 \mathrm{~h}$ at $37^{\circ} \mathrm{C}$, then run digestion reactions on a $1.5 \%(\mathrm{wt} / \mathrm{vol})$ agarose/1x TBE gel.

\section{DNA Fragmentation}

1. Transfer $50.5 \mu \mathrm{g}$ of sample in a new tube and add TLE buffer to a final volume of $655 \mu \mathrm{L}$. Split sample into 5 sonication vials (see Table of Materials) by adding $130 \mu \mathrm{L}$ of library $(10 \mu \mathrm{g})$ to each vial. Shear to a size of $\sim 400 \mathrm{bp}$ in an ultra-sonicator (see Table of Materials) using the following parameters: duty factor: 10\%; peak incident power (w): 140; cycles per burst: 200; time: $55 \mathrm{~s}$.

2. Collect sonicated sample in a fresh $2 \mathrm{~mL}$ tube.

\section{Double-sided SPRI-bead Size Selection}

1. Mix SPRI (Solid Phase Reversible Immobilization) bead solution well by inverting, transfer $1.85 \mathrm{~mL}$ of bead solution to a new tube and bring to RT for $15 \mathrm{~min}$

2. Add $350 \mu \mathrm{L}$ of water (molecular biology grade) to the sample (final volume $1 \mathrm{~mL}$ ).

3. Add $600 \mu \mathrm{L}$ of SPRI bead solution to the sample (total volume $1.6 \mathrm{~mL}$; ratio of SPRI solution to DNA: 0.6 to 1 ), incubate for $5 \mathrm{~min}$ at RT, and spin sample in a benchtop centrifuge for $2-3 \mathrm{~s}$ to collect sample.

4. Open the lid, place the sample on the magnetic separation stand for $5 \mathrm{~min}$, transfer clear supernatant into a new tube and discard beads.

5. Concentrate SPRI beads for the second size selection step: Transfer $930 \mu \mathrm{L}$ of SPRI beads into a new tube, place on the magnetic separation stand for $5 \mathrm{~min}$ and discard clear supernatant. Re-suspend the beads in $310 \mu \mathrm{L}$ of SPRI bead solution.

6. Add $300 \mu \mathrm{L}$ of concentrated SPRI beads (step 10.5) to the sample (total volume $1.9 \mathrm{~mL}$; ratio SPRI solution to DNA is now 0.9 to 1 ), incubate at RT for $5 \mathrm{~min}$, and spin sample in a benchtop centrifuge for 2-3 s. Carefully open the lid, place the tube on the magnetic separation stand for $5 \mathrm{~min}$, and discard supernatant.

7. Add $1 \mathrm{~mL}$ of freshly prepared $70 \%$ ethanol ( $\mathrm{vol} / \mathrm{vol}$ ) to the sample tube on the magnetic separation stand, incubate for $30 \mathrm{~s}$, and discard supernatant. Repeat twice.

8. Dry beads at $37^{\circ} \mathrm{C}$ in a thermomixer (tube lid open) for no more than 5 min. Add $300 \mu \mathrm{L}$ of TLE buffer to the sample, mix, and incubate for 10 min at room temperature.

9. Spin sample in a benchtop centrifuge for $2-3 \mathrm{~s}$, open the lid and place the tube on the magnetic separation stand for 5 min. Transfer clear supernatant into a new tube and discard beads.

\section{Biotin/Streptavidin Pull-down of Ligation Products}

1. Prepare buffers: $1 x$ TB buffer ( $5 \mathrm{mM}$ Tris- $\mathrm{HCl}$ pH 8.0; $0.5 \mathrm{mM}$ EDTA; $1 \mathrm{M} \mathrm{NaCl} ; 0.05 \%$ Tween 20$) ; 2 x$ NTB buffer (10 mM Tris-HCl pH $8.0 ; 1$ mM EDTA; $2 \mathrm{M} \mathrm{NaCl}$ ); 1x NTB buffer (5 mM Tris-HCl pH 8.0; 0.5 mM EDTA; $1 \mathrm{M} \mathrm{NaCl}$ ).

2. Add $200 \mu \mathrm{L}$ of magnetic streptavidin-coupled beads (see Table of Materials) into a new tube, place it on the magnetic separation stand for 1 min and remove supernatant.

3. Wash beads twice with $500 \mu \mathrm{L}$ of $1 \times$ TB buffer.

1. For each wash step during the biotin pull-down, end repair and removal of biotin at non-ligated DNA ends, dATP tailing, and adapter ligation steps, re-suspend the beads in the corresponding buffer, rotate at RT and $15 \mathrm{rpm}$ for $3 \mathrm{~min}$, spin the tube in a benchtop centrifuge for $2-3 \mathrm{~s}$, place the tube on the magnetic separation stand for $3 \mathrm{~min}$ and remove supernatant.

4. Re-suspend beads in $300 \mu \mathrm{L}$ of $2 x$ NTB buffer. Mix beads and sample (600 $\mu \mathrm{L}$ total volume) and incubate at RT for 15 min on a rotating wheel at $3 \mathrm{rpm}$.

5. Reclaim beads on the magnetic separation stand for $3 \mathrm{~min}$ and remove the clear supernatant. Wash beads twice in $500 \mu \mathrm{L}$ of $1 \times \mathrm{NTB}$ buffer first and then in $200 \mu \mathrm{L}$ of $1 \mathrm{x}$ ligation buffer. Re-suspend the beads in $50 \mu \mathrm{L}$ of $10 \mathrm{x}$ ligation buffer.

\section{End Repair and Removal of Biotin at Non-ligated DNA Ends}

1. Combine the sample ( $50 \mu \mathrm{L}$ in total) with $50 \mu \mathrm{L}$ of $2.5 \mathrm{mM}$ dNTP mix $(12.5 \mu \mathrm{L}$ of $10 \mathrm{mM}$ of each dNTP), $18.1 \mu \mathrm{L}$ of $3,000 \mathrm{U} / \mathrm{mL}$ T4 DNA Polymerase, $18.1 \mu \mathrm{L}$ of $10,000 \mathrm{U} / \mathrm{mL}$ T4 PNK, $3.7 \mu \mathrm{L}$ of $5,000 \mathrm{U} / \mathrm{mL}$ DNA polymerase I large (Klenow) fragment, and $360.1 \mu \mathrm{L}$ of $\mathrm{H}_{2} \mathrm{O}$.

2. Mix and incubate at $20^{\circ} \mathrm{C}$ for $1 \mathrm{~h}$, shaking $5 \mathrm{~s}$ at $700 \mathrm{rpm}$ every $2 \mathrm{~min}$ in a thermomixer.

3. Reclaim beads on the magnetic separation stand, remove the clear supernatant, and wash beads twice in $500 \mu \mathrm{L}$ of $1 \times \mathrm{TB}$ buffer.

4. Wash beads in $500 \mu \mathrm{L}$ of $1 \times$ NTB buffer, followed by one wash in $500 \mu \mathrm{L}$ of $1 \mathrm{x}$ TLE . 
5. Reclaim beads on the magnetic separation stand, remove the clear supernatant, and re-suspend beads in $415 \mu \mathrm{L}$ of $1 \times \mathrm{TLE}$ buffer.

\section{3. dATP Tailing}

1. Combine sample $(415 \mu \mathrm{L})$ with $50 \mu \mathrm{L}$ of $10 x$ restriction buffer $2,5 \mu \mathrm{L}$ of $10 \mathrm{mM}$ dATP, and $30 \mu \mathrm{L}$ of $5 \mathrm{U} / \mu \mathrm{L}$ Klenow exo-minus.

2. Mix and incubate at $37^{\circ} \mathrm{C}$ for $30 \mathrm{~min}$, shaking $5 \mathrm{~s}$ at $700 \mathrm{rpm}$ every $2 \mathrm{~min}$ in a thermomixer.

3. Reclaim beads on the magnetic separation stand, remove the clear supernatant, and wash beads twice in $500 \mu \mathrm{L}$ of $1 \times \mathrm{TB}$ buffer.

4. Wash beads in $500 \mu \mathrm{L}$ of $1 \times$ NTB buffer.

\section{Adapter Ligation}

1. Wash beads in $200 \mu \mathrm{L}$ of $1 \mathrm{x}$ ligation reaction buffer (see Table of Materials).

2. Re-suspend beads in $200 \mu \mathrm{L}$ of $1 \mathrm{x}$ ligation reaction buffer. Add $4 \mu \mathrm{L}$ of DNA ligase (see Table of Materials) and $16 \mu \mathrm{L}$ of $15 \mu \mathrm{M}$ pre-annealed PE adapters (pre-anneal the PE adapters by mixing equal volumes of PE adapter 1 and PE adapter 2 (both at $30 \mu \mathrm{M}$ ) and incubating for a few minutes at RT). Incubate at RT for 15 min.

3. Reclaim beads on the magnetic separation stand, remove the clear supernatant, and wash beads twice in $500 \mu \mathrm{L}$ of $1 \times \mathrm{TB}$ buffer.

4. Wash beads in $500 \mu \mathrm{L}$ of $1 \mathrm{x}$ NTB buffer. Then, wash beads in $100 \mu \mathrm{L}$ of $1 \mathrm{x}$ restriction buffer 2 , re-suspend beads in $50 \mu \mathrm{L}$ of $1 \mathrm{x}$ restriction buffer 2, and transfer into a new tube.

\section{Hi-C Library Amplification}

1. Prepare PCR master mix: $100 \mu \mathrm{L}$ of $5 x$ Phusion buffer; $6 \mu \mathrm{L}$ of $25 \mu \mathrm{M}$ PE PCR primer $1.0 ; 6 \mu \mathrm{L}$ of $25 \mu \mathrm{M}$ PE PCR primer $2.0 ; 14 \mu \mathrm{L}$ of dNTP $\operatorname{mix}\left(10 \mathrm{mM}\right.$ each); $6 \mu \mathrm{L}$ of Phusion polymerase; $318 \mu \mathrm{L}$ of $\mathrm{H}_{2} \mathrm{O}$.

2. Mix PCR master mix with the beads (500 $\mu \mathrm{L}$ in total), divide in 10 aliquots of $50 \mu \mathrm{L}$, and amplify by PCR using the following conditions: 30 s at $98^{\circ} \mathrm{C}$

7 cycles of: $10 \mathrm{~s}$ at $98^{\circ} \mathrm{C} ; 30 \mathrm{~s}$ at $65^{\circ} \mathrm{C} ; 30 \mathrm{~s}$ at $72{ }^{\circ} \mathrm{C}$

7 min at $72{ }^{\circ} \mathrm{C}$

3. Collect PCR reactions into a new tube, reclaim beads on the magnetic separation stand, and transfer supernatant ( $500 \mu \mathrm{L})$ into a new tube.

4. Purify the library DNA using SPRI beads.

1. Mix SPRI beads, transfer $460 \mu \mathrm{L}$ of beads in a new tube, and bring to RT for $15 \mathrm{~min}$. Add $450 \mu \mathrm{L}$ of SPRI beads to the PCR reactions (final volume $950 \mu \mathrm{L}$ ), incubate for $5 \mathrm{~min}$ at RT, and spin sample in a benchtop centrifuge for $2-3 \mathrm{~s}$ to collect sample.

2. Open the lid, place the sample on the magnetic separation stand for $5 \mathrm{~min}$, and remove supernatant.

3. Keeping the beads on the magnetic separation stand, add $1 \mathrm{~mL}$ of $70 \%$ ethanol ( $\mathrm{vol} / \mathrm{vol})$ to sample tube over an area clear of beads, leave for $30 \mathrm{~s}$, and discard supernatant.

4. Repeat step 15.4 .3 twice more.

5. Dry beads at $37^{\circ} \mathrm{C}$ in a thermomixer (tube lid open) for no more than $5 \mathrm{~min}$.

6. Add $51 \mu \mathrm{L}$ of TLE buffer to the sample, mix, and incubate for $10 \mathrm{~min}$ at $37^{\circ} \mathrm{C}$, shaking at $950 \mathrm{rpm}$ in a thermomixer.

7. Spin sample in a benchtop centrifuge for $2-3 \mathrm{~s}$, open the lid and place the tube on the magnetic separation stand for 5 min. Transfer clear supernatant into a new tube and discard beads.

8. Quantify the concentration of the Hi-C library. After 7 rounds of PCR amplification, we routinely obtain $500-1,500 \mathrm{ng}$ of Hi-C library.

\section{Hybrid In-solution Capture}

NOTE: Blocker and buffer (SHS1-4) solutions below are from the SureSelect kit (see Table of Materials).

1. Transfer $500 \mathrm{ng}$ to $1 \mu \mathrm{g}$ of $\mathrm{Hi}-\mathrm{C}$ library into a new tube and evaporate sample on a vacuum Concentrator (see Table of Materials; $45^{\circ} \mathrm{C}$; vacuum pressure: level 30.0 , ramp 5 ) until dry.

2. Re-suspend evaporated $\mathrm{Hi}-\mathrm{C}$ library by adding $3.6 \mu \mathrm{L}$ of $\mathrm{H}_{2} \mathrm{O}$ (molecular biology grade), $2.5 \mu \mathrm{L}$ of blocker $1,2.5 \mu \mathrm{L}$ of blocker 2 , and $0.6 \mu \mathrm{L}$ of custom blocker.

3. Transfer sample into a well of a new PCR tube strip, close with a PCR cap strip and place on ice. Label as "D" (for Hi-C DNA).

4. Prepare the hybridization buffer: $12.5 \mu \mathrm{L}$ of SHS1 buffer; $0.5 \mu \mathrm{L}$ of SHS2 buffer; $5 \mu \mathrm{L}$ of SHS3 buffer; $6.5 \mu \mathrm{L}$ of SHS4 buffer.

5. Incubate at $65^{\circ} \mathrm{C}$ for $5 \mathrm{~min}$ in a thermomixer. Transfer into a well of a new PCR tube strip, close with a PCR cap strip and keep at RT. Label as "H" (for hybridization buffer).

6. Into a well of a new PCR tube strip, mix $5 \mu \mathrm{L}$ of $100 \mathrm{ng} / \mu \mathrm{L}$ biotinylated RNA probes (store at $-80^{\circ} \mathrm{C}$ and thaw on ice just before use); $0.5 \mu \mathrm{L}$ of SRNase $B$ (RNase inhibitor) and $1.5 \mu \mathrm{L}$ of $\mathrm{H}_{2} \mathrm{O}$ (molecular biology grade).

7. Close the PCR tube strip with a PCR cap strip and place on ice. Label as "R" (for RNA).

8. Set up PCR machine using the following parameters: 5 min at $95^{\circ} \mathrm{C} ; 25 \mathrm{~h}$ at $65^{\circ} \mathrm{C}$; lid heated; $29 \mu \mathrm{L}$ PCR reaction volume.

NOTE: Proceed as quickly as possible during all procedures while the PCR machine is running in order to avoid sample evaporation.

9. Place the "D" PCR tube strip in the PCR machine, close the PCR machine lid, and start the PCR reaction. When the PCR program reaches $65^{\circ} \mathrm{C}$, open the PCR machine lid and place the "H" PCR tube strip in the PCR machine. Close the PCR machine lid and incubate for 3 min. Open the PCR machine lid, place the "R" PCR tube strip on the PCR machine, and close the PCR machine.

10. After 2 min, open the PCR machine lid and all PCR tube strips. Transfer $13 \mu \mathrm{L}$ of well "H" into well "R", then all volume of well "D" into well "R". Pipet up and down 3 times to mix the reaction, close the PCR tube strip, remove the "H" and "D" PCR tube strips, and close PCR machine lid. Incubate the reaction at $65^{\circ} \mathrm{C}$ for $24 \mathrm{~h}$. 


\section{Isolation of Promoter Fragment-containing Ligation Products}

NOTE: The following steps are recommended to be done with SureSelect adapter kit and library (see Table of Materals).

1. Pre-warm $1.5 \mathrm{~mL}$ of wash buffer 2 per sample at $65^{\circ} \mathrm{C}$ in advance.

2. Add $60 \mu \mathrm{L}$ of streptavidin-coupled magnetic beads (see Table of Materials) into a new tube, place on the magnetic separation stand for 1 min and remove supernatant.

3. Wash beads three times with $200 \mu \mathrm{L}$ of $1 \mathrm{x}$ binding buffer. NOTE: For each wash step during the post-capture isolation of promoter-containing ligation products, re-suspend beads in the corresponding buffer, rotate for $3 \mathrm{~min}$ at RT and $15 \mathrm{rpm}$ on a rotating wheel, softly spin the tube in a benchtop centrifuge for $2-3 \mathrm{~s}$ to collect sample, place the tube on the magnetic separation stand for $3 \mathrm{~min}$, and remove supernatant.

4. Re-suspend beads in $200 \mu \mathrm{L}$ of $1 \mathrm{x}$ binding buffer. Open the PCR machine and the PCR tube strip (while the PCR program is still running) and transfer the hybridization reaction into the tube with the magnetic beads. Incubate at RT for 30 min on a rotating wheel at $3 \mathrm{rpm}$.

5. Reclaim beads on the magnetic separation stand and remove the clear supernatant. Re-suspend beads into $500 \mu \mathrm{L}$ of wash buffer 1 , mix, and incubate for $15 \mathrm{~min}$ at $20^{\circ} \mathrm{C}$ while shaking at $950 \mathrm{rpm}$ in a thermomixer.

6. Reclaim beads on the magnetic separation stand for $3 \mathrm{~min}$ and remove the clear supernatant. Re-suspend beads into $500 \mu \mathrm{L}$ of wash buffer 2 , mix and incubate $10 \mathrm{~min}$ at $65^{\circ} \mathrm{C}$ while shaking at $950 \mathrm{rpm}$ in a thermomixer. Repeat step 17.5 twice more.

7. Reclaim beads on the magnetic separation stand, remove the clear supernatant and re-suspend beads in $200 \mu \mathrm{L}$ of $1 \mathrm{x}$ restriction buffer 2 . Reclaim beads on the magnetic separation stand, remove supernatant and re-suspend beads into $30 \mu \mathrm{L}$ of $1 \mathrm{x}$ restriction buffer 2 .

\section{PCHi-C Library Amplification}

1. Prepare PCR master mix: $60 \mu \mathrm{L}$ of $5 x$ PCR buffer (Phusion buffer), $3.6 \mu \mathrm{L}$ of $25 \mu \mathrm{M}$ PE PCR primer 1.0, 3.6 $\mu \mathrm{L}$ of $25 \mu \mathrm{M}$ PE PCR primer 2.0, $8.4 \mu \mathrm{L}$ of dNTP mix (10 mM each), $3.6 \mu \mathrm{L}$ of Phusion polymerase, and $190.8 \mu \mathrm{L}$ of $\mathrm{H}_{2} \mathrm{O}$.

2. Mix PCR master mix with the beads ( $300 \mu \mathrm{L}$ in total), divide in 6 aliquots of $50 \mu \mathrm{L}$, and PCR-amplify using the following conditions:

$30 \mathrm{~s}$ at $98^{\circ} \mathrm{C}$

4 cycles of: $10 \mathrm{~s}$ at $98^{\circ} \mathrm{C}, 30 \mathrm{~s}$ at $65^{\circ} \mathrm{C}, 30 \mathrm{~s}$ at $72^{\circ} \mathrm{C}$

7 min at $72{ }^{\circ} \mathrm{C}$

3. Collect all PCR reactions in a new tube, reclaim the beads on the magnet, and transfer supernatant ( $300 \mu \mathrm{L}$; contains $\mathrm{PCHi}-\mathrm{C}$ library) in to a new tube.

4. Purify the PCHi-C library using SPRI beads, following the steps described above under 15.4 .

5. Quantify the concentration of the PCHi-C library.

\section{Representative Results}

Promoter Capture Hi-C has been used to enrich mouse ${ }^{7,34,36,39}$ and human ${ }^{33,35,37,38} \mathrm{Hi}-\mathrm{C}$ libraries for promoter interactions. A similar protocol (named HiCap) has been described by the Sandberg group ${ }^{40}$. Figure 1A shows the schematic workflow for Promoter Capture Hi-C. In the protocol described here, Hi-C libraries are generated using in-nucleus ligation ${ }^{41}$, which results in a significantly reduced number of spurious ligation products ${ }^{42}$. For $\mathrm{PCHi}-\mathrm{C}$, highly complex mouse or human $\mathrm{Hi}-\mathrm{C}$ libraries are subjected to in-solution hybridization and capture using 39,021 biotinylated RNAs complementary to 22,225 mouse promoter-containing Hindll restriction fragments, or 37,608 biotinylated RNAs targeting 22,076 human promoter-containing HindIII restriction fragments, respectively. Promoter containing restriction fragments can be targeted at either or both ends by individual biotinylated RNAs (Figure 1B). We found that capture of both ends improved coverage of individual promoters (Figure 1C; raw sequence reads) nearly two-fold, as expected. Thus, whenever possible (i.e., in non-repetitive regions), we advise to use biotinylated RNAs complementary to both ends of a restriction fragment to be captured.

To assess PCHi-C library quality at an early stage during library preparation, we perform two controls after DNA ligation and purification, as previously described ${ }^{31}$. The first is to use specific primer pairs to amplify ligation products as in $3 C^{27}$. We use primer pairs (Table 1) to amplify cell-type invariant long-range ligation products, such as between the Myc gene and its known enhancers located approximately $2 \mathrm{Mb}$ away (Figure 2A) or between genes of the Hist1 locus (separated by $1.5 \mathrm{Mb}$ ), and between two regions located in close linear proximity ('short-range control').

The second quality control is carried out to determine the efficiency of biotin incorporation during Klenow-mediated fill-in of restriction site overhangs with biotin-dATP. Successful Klenow fill-in and subsequent blunt-end ligation results in the disappearance of the original restriction site between the DNA molecules of a ligation product, and in the case of HindlII in the formation of a new Nhel recognition site (Figure 2B). The ratio of the HindllI to Nhel digested ligation product is a direct readout of biotin incorporation efficiency. A poor quality Hi-C library will show a high level of Hindlll digestion, whereas high-quality libraries have near-complete Nhel digestion of ligation products (Figure 2B).

After Hi-C library preparation (i.e., after biotin-streptavidin pull down of size-selected Hi-C ligation products, adapter ligation and pre-capture $\mathrm{PCR}$ ), the integrity and size distribution of the $\mathrm{Hi}-\mathrm{C}$ library is assessed by Bioanalyzer (Figure 2C). The same control is carried out at the end of PCHi-C library preparation (i.e., after hybridization capture of promoter-containing ligation products and post-capture PCR). Comparison of the $\mathrm{Hi}-\mathrm{C}$ and $\mathrm{PCHi}-\mathrm{C}$ Bioanalyzer profiles shows that as expected, $\mathrm{Hi}-\mathrm{C}$ libraries are much more concentrated than the corresponding $\mathrm{PCH}-\mathrm{C}$ libraries, but the size distribution of the libraries is highly similar, indicating that the capture step in PCHi-C does not introduce a size bias (Figure 2C, D). 
After paired-end sequencing, the PCHi-C reads are mapped, quality controlled and filtered using the HiCUP pipeline ${ }^{43}$. High-quality PCHi-C libraries contain between $70-90 \%$ 'valid pairs' (i.e., paired-end sequence reads between two restriction fragments that are not neighboring on the linear genomic map; Figure 3A, B). Using the in-nucleus ligation protocol ${ }^{41,42}$, the percentage of trans read pairs (i.e., paired-end sequence reads between two restriction fragments that are located on different chromosomes) are usually low, between 5 and $25 \%$, reflecting the existence of chromosome territories, and indicating good library quality. Direct comparison of the percentage of 'valid pairs' between $\mathrm{Hi}-\mathrm{C}$ libraries and their corresponding PCHi-C libraries ${ }^{35}$, shows that in all cases the percentage of valid pairs is higher in the PCHi-C libraries (Figure 3B). This is accompanied by a reduction in the percentage of non-valid 'same fragment internal' reads in PCHi-C (Figure 3C). This is expected, as the capture step not only enriches for promoter-containing ligation products, but also for restriction fragment ends, due to the position of the capture oligos on the restriction fragments (see Figure 1B).

After HiCUP filtering, we determine the capture efficiency. PCHi-C libraries contain three types of valid sequence reads after HiCUP filtering: 1.) Promoter: genome reads (i.e., reads between a captured promoter fragment and a non-promoter Hindlll restriction fragment anywhere in the genome)

2.) Promoter: promoter reads (reads between two captured promoter fragments)

3.) Genome: genome reads (background Hi-C ligation products where neither of the ligation product partners maps to a captured promoter).

These are discarded prior to downstream analyses.

High-quality PCHi-C libraries have capture efficiencies (sum of categories 1 and 2 above) between 65-90\% (Figure 3D). A direct comparison to $\mathrm{Hi}-\mathrm{C}$ libraries shows that $\mathrm{PCHi}-\mathrm{C}$ results in a $\sim 15$-fold enrichment for promoter-containing ligation products (Figure 3D), in some cases 17-fold. This is close to the hypothetical maximum (19.6-fold) enrichment for $\mathrm{PCHi}-\mathrm{C}$, which is dependent on the percentage of the genome restriction fragments covered by the capture system. Greater enrichment can be achieved by designing capture systems targeting fewer restriction fragments $^{44,45,46}$.

Analysis of promoter interactomes demonstrates cell type and lineage-specificity ${ }^{33,34,35}$, with pronounced changes during cellular differentiation ${ }^{37,38,39}$. Figures $\mathbf{4}$ and $\mathbf{5}$ show examples of lineage specificity and differentiation dynamics at specific promoters. For example, $A L A D$ is constitutively expressed in all cells but its expression is upregulated in erythroblasts ${ }^{47}$. The $A L A D$ promoter contacts several distal fragments in all hematopoietic cells and engages in additional interactions specifically in erythroblasts (Figure 4). IL-8 shows no statistically significant interactions in B cells, very few interactions in T cells, but dozens of interactions in cells of the myeloid lineage, including cell-type specific interactions in monocytes, neutrophils and megakaryocytes (Figure 5). These examples demonstrate how PCHi-C can be used to unravel cell-type specific interactomes and identify promoter-interacting regions with regulatory potential. 
A

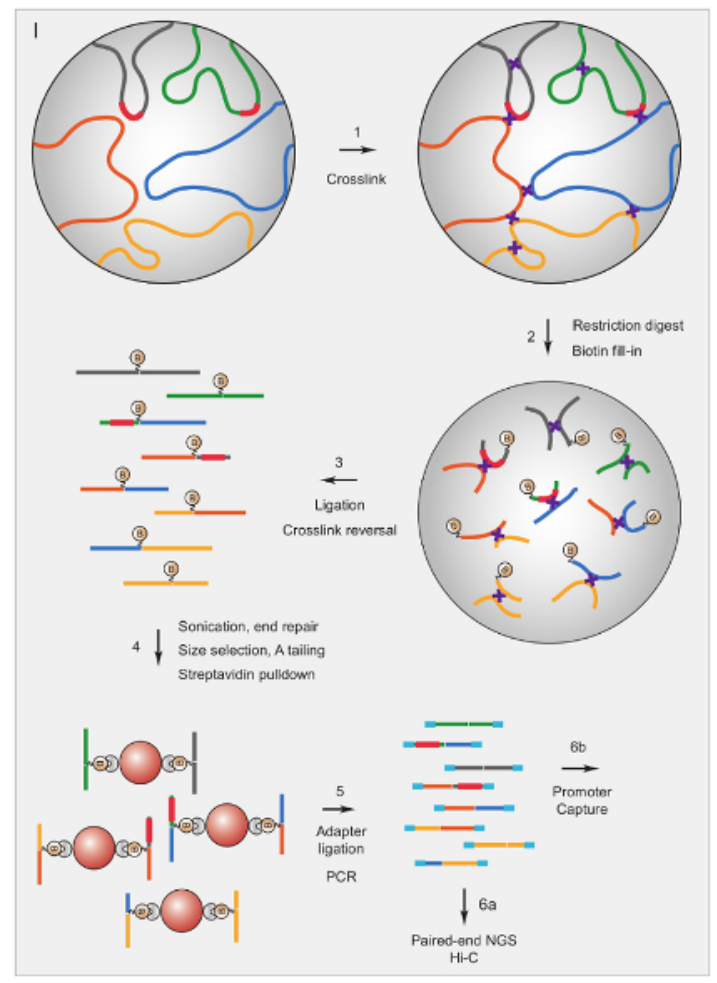

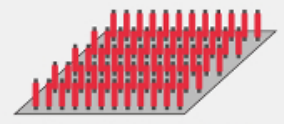

37,608 bark probes targeting 22,076 restriction fragments containing 31,253 annotated human promoters

$1 \downarrow$ Elution and PCR

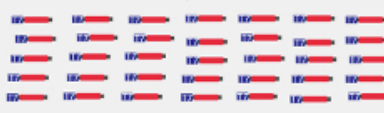

$2 \downarrow$ Biotin-UTP transcription

(2) 2 (2) 2 (2) 2 이

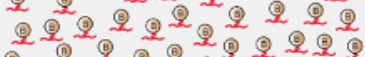

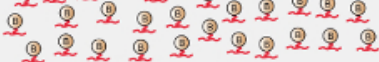

$3 \downarrow \begin{gathered}\text { Promoter capture } \\ \text { hybridization }\end{gathered}$

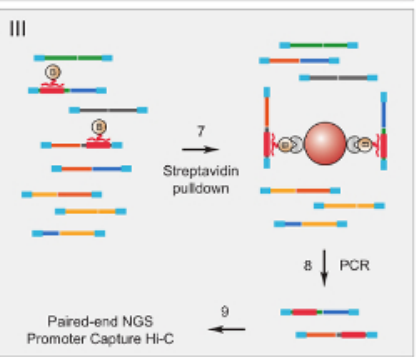

B

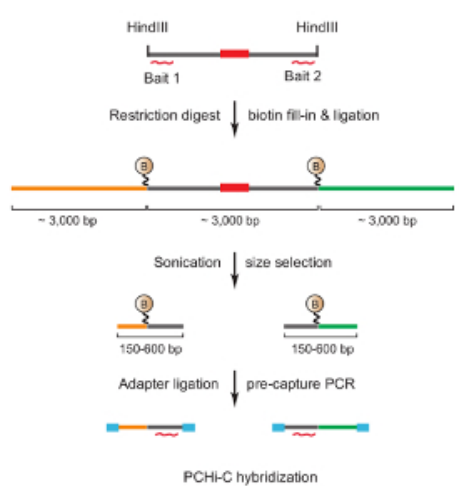

C

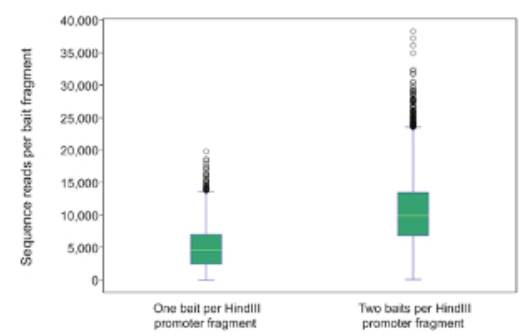

Figure 1: Promoter Capture Hi-C rationale and capture bait design. (A) Schematic workflow of $\mathrm{PCHi}-\mathrm{C}$. In-nucleus ligation $\mathrm{Hi}-\mathrm{C}^{41,42}(\mathrm{I})$ is followed by in-solution hybridization with biotinylated RNA baits (II) targeting the restriction fragments of all human (depicted here) or mouse gene promoters (III). (B) Bait design for PCHi-C. Biotinylated RNA capture baits (red curved lines) are designed against the ends of promotercontaining restriction fragments (grey; note that the promoter sequences themselves (red) are only targeted by the RNA capture baits if they are located at restriction fragment ends). Ligation products consisting of promoter-containing restriction fragments (grey) and their interacting restriction fragments (yellow and green) are isolated through sequence-complementarity hybridization between RNA bait and DNA target, and subsequent biotin-streptavidin pulldown, as shown in A. (C) Comparison of PCHi-C capture efficiency for promoter-containing restriction fragments targeted by one RNA bait capture probe vs two RNA bait capture probes (see schematic in B). Please click here to view a larger version of this figure. 
A

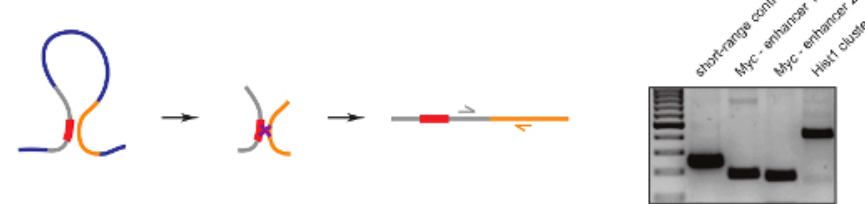

B

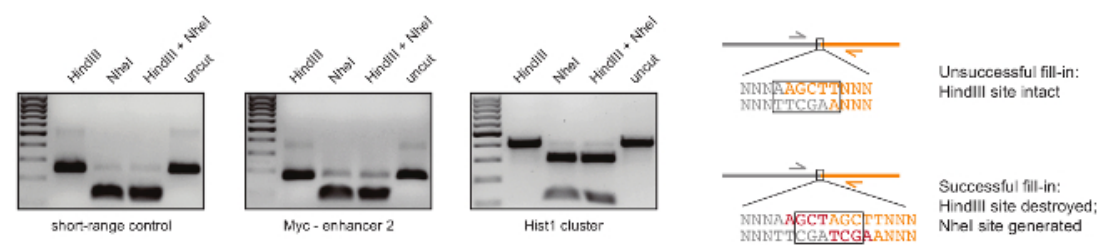

C

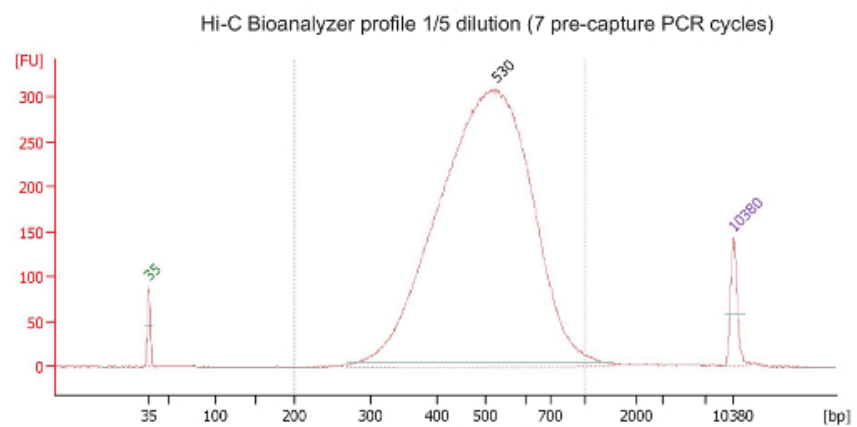

D

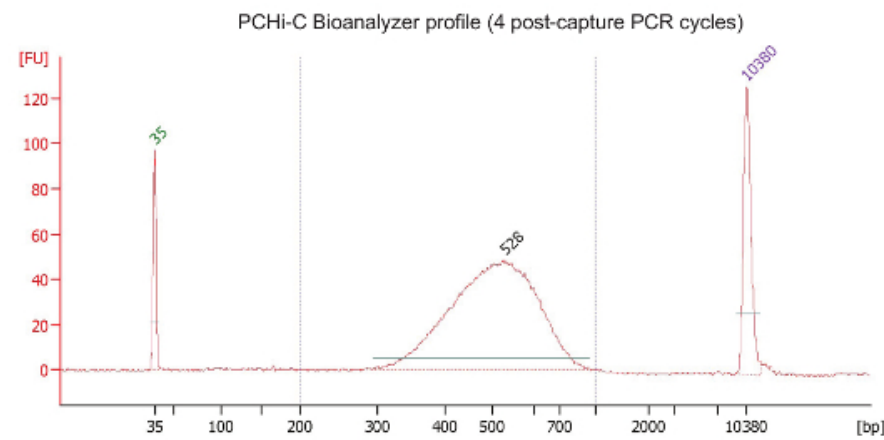

Figure 2: PCHi-C pre-sequencing quality controls. (A) Left, schematic of spatial juxtaposition between promoter and PIR, resulting in a Hi-C ligation product consisting of a promoter-containing restriction fragment (grey; promoter sequence in red) and a PIR restriction fragment (yellow). Right, DNA gel electrophoresis showing examples of $\mathrm{Hi}-\mathrm{C}$ ligation products amplified using specific primer pairs (as depicted in schematic on the left). (B) Left, representative examples of HindIII, Nhel and HindIII/Nhel restriction digests of Hi-C ligation products (PCR products shown in A). Right, schematic of DNA sequence after Hi-C ligation following unsuccessful (top) or successful (bottom) dNTP Klenow fill-in of restriction junctions and subsequent ligation. (C) Representative Hi-C library bioanalyzer profile (1/5 dilution). (D) Representative PCHi-C library bioanalyzer profile (no dilution). Please click here to view a larger version of this figure. 
A

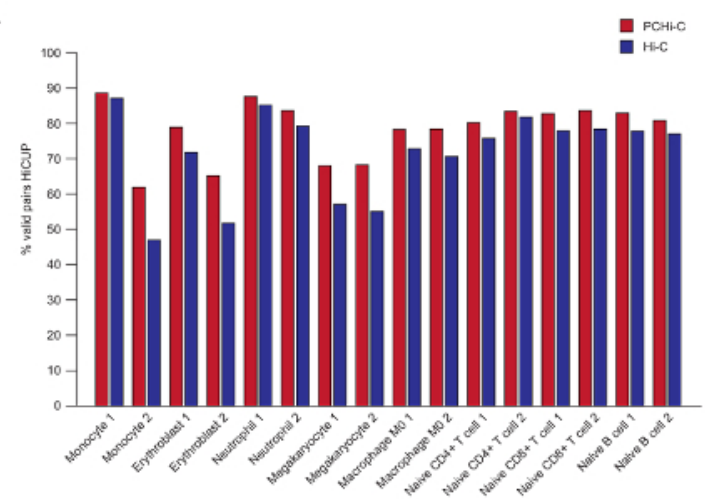

C
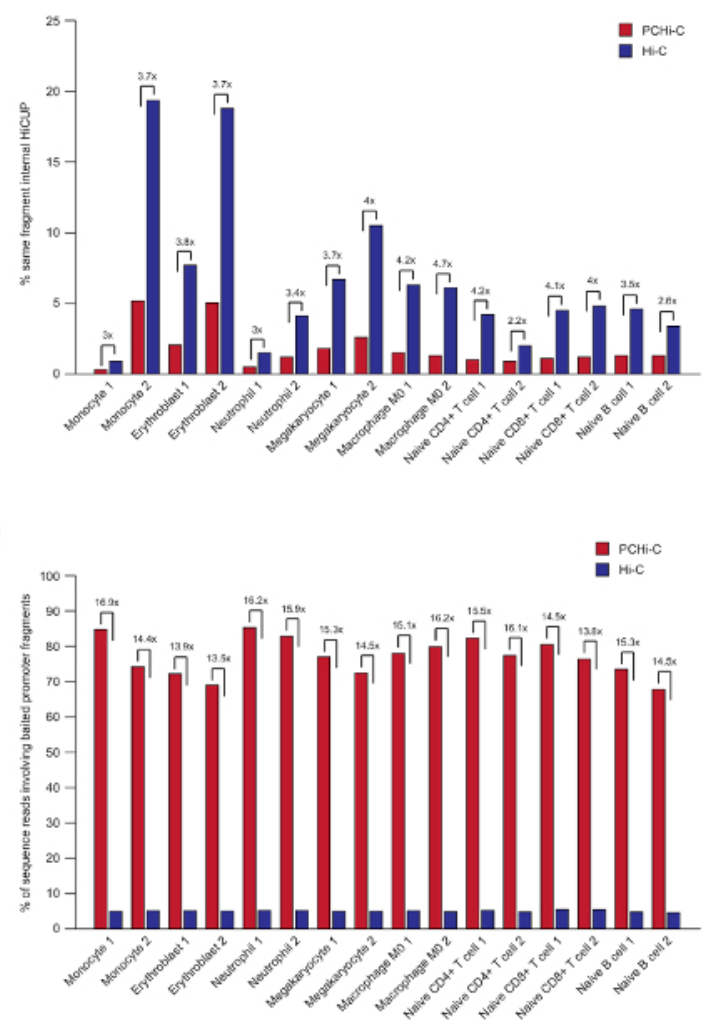

B

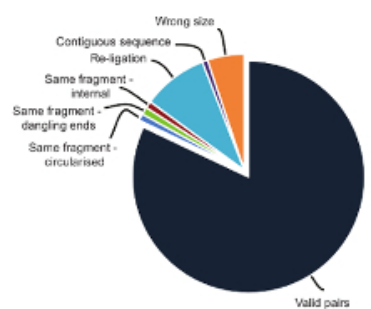

Figure 3: $\mathrm{PCHi}-\mathrm{C}$ post-sequencing quality controls. (A) Comparison of percentage valid sequence read pairs after HiCUP ${ }^{43}$ processing in $\mathrm{PCHi}-\mathrm{C}$ vs corresponding Hi-C libraries (data from Javierre et al., $2016^{35}$ ). (B) Representative HiCUP PCHi-C result showing valid read pairs, and other sequence categories that are discarded prior to downstream analyses (data from Javierre et al., 2016 ${ }^{35}$ ). (C) Comparison of percentage 'same fragment internal' reads after HiCUP processing in $\mathrm{PCHi}-\mathrm{C}$ vs corresponding Hi-C libraries (data from Javierre et al., $2016^{35}$ ). (D) Comparison of percentage sequence reads involving baited promoter fragments (capture efficiency) in PCHi-C vs corresponding Hi-C libraries (data from Javierre et al., $2016^{35}$ ). Please click here to view a larger version of this figure. 


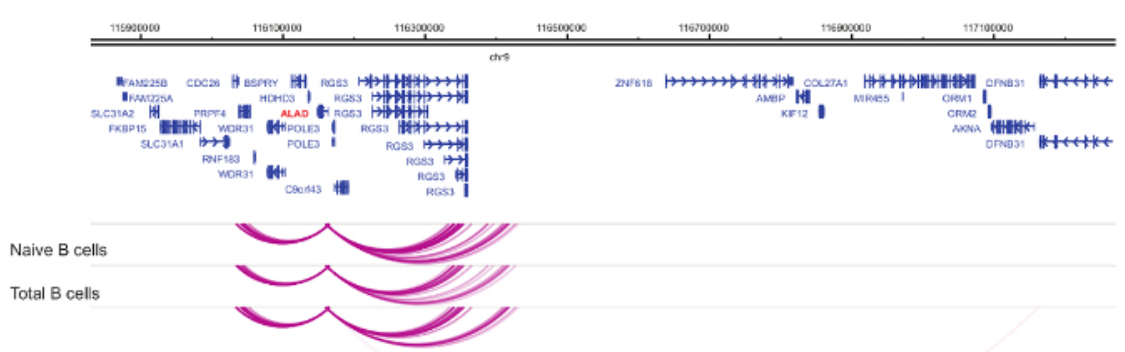

Fetal thymus

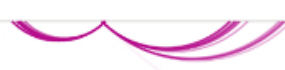

Activated $\mathrm{CD} 4+\mathrm{T}$ cells

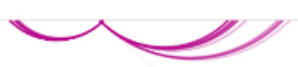

Non-activated CD4 $+T$ cells

Total $\mathrm{CD} 4+\mathrm{T}$ cells

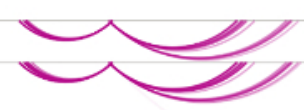

Naive CD $8+T$ cells

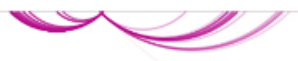

Naive CD4+T cells

Total $\mathrm{CD} 8+\mathrm{T}$ cells

Monocytes

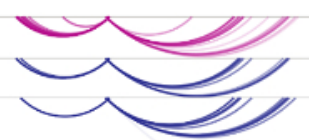

Neutrophils

Macrophages M2

Macrophages M1

Macrophages MO

Endothelial precursors

Megakaryocytes

thr

Erythroblasts

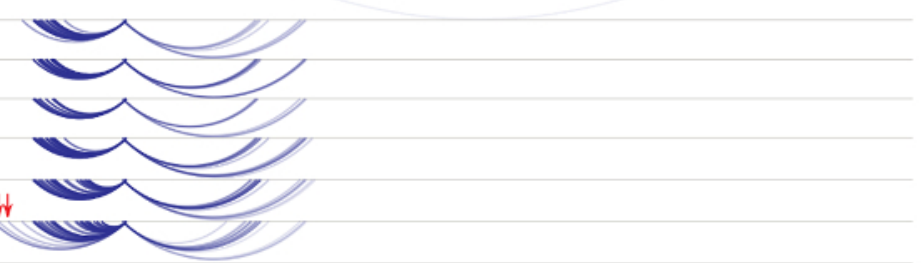

Figure 4: ALAD PCHi-C profile in human hematopoietic cells. Promoter interactions of myeloid cell types are shown as blue arches, and promoter interactions of lymphoid cell types are shown as purple arches. Erythroblast-specific interactions are indicated by red arrows (data from Javierre et al., $2016^{35}$ ). Please click here to view a larger version of this figure. 


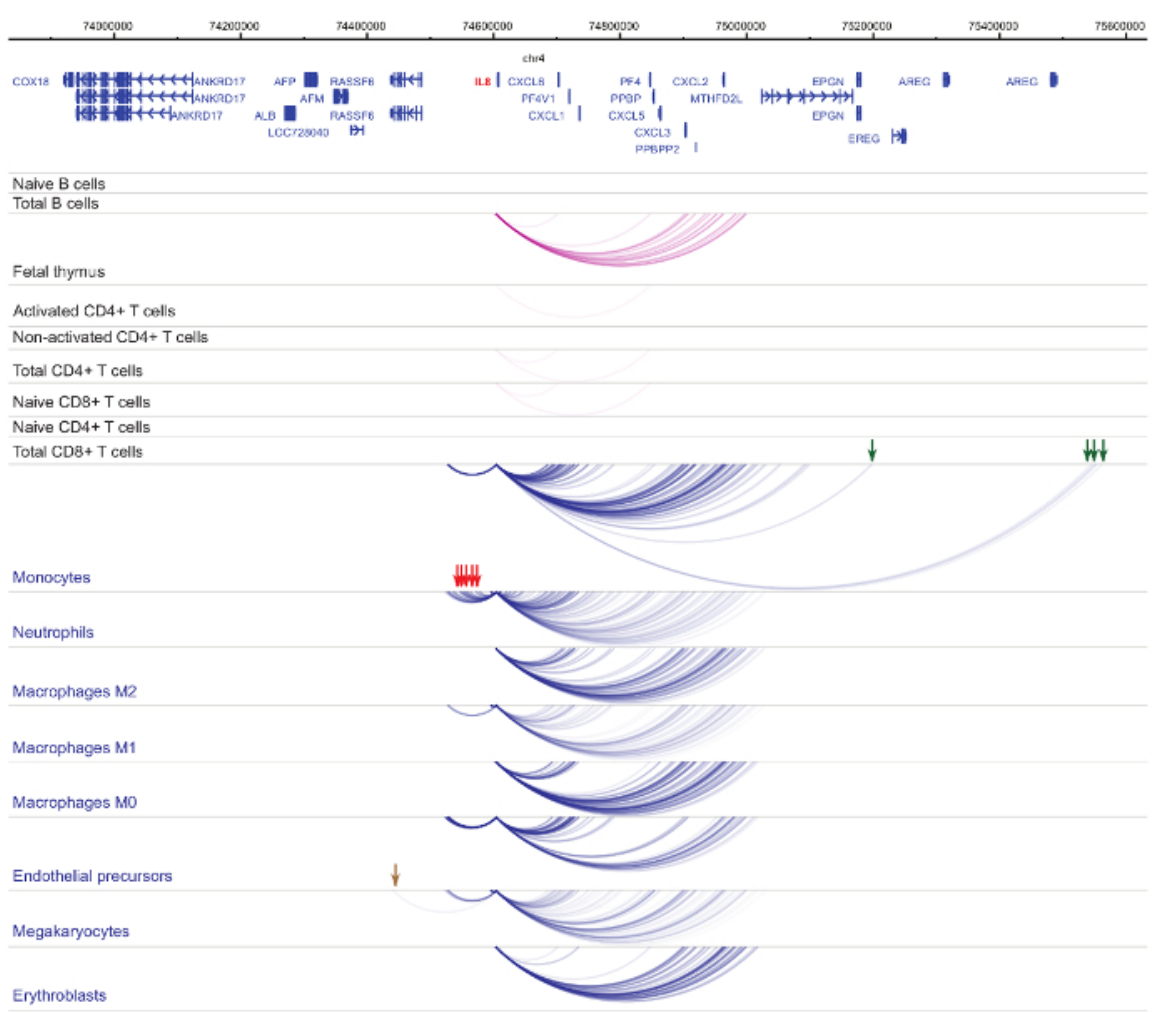

Figure 5: IL8 PCHi-C profile in human hematopoietic cells. Promoter interactions of myeloid cell types are shown as blue arches, and promoter interactions of lymphoid cell types are shown as purple arches. Monocyte-specific interactions are indicated by green arrows, neutrophil-specific interactions are indicated by red arrows, and a megakaryocyte-specific interaction is indicated by a brown arrow (data from Javierre et al., $2016^{35}$ ). Please click here to view a larger version of this figure. 


\begin{tabular}{|c|c|c|c|c|c|c|}
\hline \multicolumn{7}{|l|}{ Human } \\
\hline Name & Sequence & Chromosome & Strand & $\begin{array}{l}\text { Start GRCh38/ } \\
\text { hg38 }\end{array}$ & \begin{tabular}{|l|} 
End GRCh38/ \\
hg38
\end{tabular} & \begin{tabular}{|l|} 
Primer \\
combinations \\
to test 3C \\
interactions \\
and biotin \\
incorporation
\end{tabular} \\
\hline $\begin{array}{l}\text { hs AHF64 } \\
\text { Dekker }\end{array}$ & GCATGCATTAGCCTCTGCTGTTCTCTGAAATO & 11 & + & 116803960 & 116803991 & $\begin{array}{l}\text { use in } \\
\text { combination } \\
\text { with hs AHF66 } \\
\text { Dekker }\end{array}$ \\
\hline $\begin{array}{l}\text { hs AHF66 } \\
\text { Dekker }\end{array}$ & СTGTCCAAGTACATTCCTGTTCACAAACCC & 11 & + & 116810219 & 116810248 & $\begin{array}{l}\text { use in } \\
\text { combination } \\
\text { with hs AHF64 } \\
\text { Dekker }\end{array}$ \\
\hline hs MYC locus & GGAGAACCGGTAATGGCAAA & 8 & - & 127733814 & 127733833 & $\begin{array}{l}\text { use in } \\
\text { combination } \\
\text { with hs MYC } \\
+1820 \text { or hs } \\
\text { MYC }-538\end{array}$ \\
\hline $\begin{array}{l}\text { hs MYC } \\
+1820\end{array}$ & AAAATGCCCATTTCСТTCTCC & 8 & + & 129554527 & 129554547 & $\begin{array}{l}\text { use in } \\
\text { combination } \\
\text { with hs MYC } \\
\text { locus }\end{array}$ \\
\hline hs MYC -538 & TGCCTGATGGATAGTGCTTTC & 8 & - & 127195696 & 127195716 & $\begin{array}{l}\text { use in } \\
\text { combination } \\
\text { with hs MYC } \\
\text { locus }\end{array}$ \\
\hline hs HIST1 F & AAGCAGGAAAAGGCATAGCA & 6 & + & 26207174 & 26207193 & $\begin{array}{l}\text { use in } \\
\text { combination } \\
\text { with hs HIST1 } \\
\mathrm{R}\end{array}$ \\
\hline hs HIST1 R & TCTTGGGTTGTGGGACTTTC & 6 & + & 27771575 & 27771594 & $\begin{array}{l}\text { use in } \\
\text { combination } \\
\text { with hs HIST1 } \\
\text { F }\end{array}$ \\
\hline \multicolumn{7}{|l|}{ Mouse } \\
\hline & Sequence & Chromosome & Strand & $\begin{array}{l}\text { Start } \\
\text { GRCm38/ } \\
\text { mm10 }\end{array}$ & $\begin{array}{l}\text { End GRCm38/ } \\
\text { mm10 }\end{array}$ & \begin{tabular}{|l|} 
Primer \\
combinations \\
to test 3C \\
interactions \\
and biotin \\
incorporation
\end{tabular} \\
\hline & TCATGAGTTCCCCACATCTTTG & 8 & + & 84841090 & 84841111 & $\begin{array}{l}\text { use in } \\
\text { combination } \\
\text { with mm Calr2 }\end{array}$ \\
\hline & CTGTGGGCACCAGATGTGTAAAT & 8 & + & 84848519 & 84848541 & $\begin{array}{l}\text { use in } \\
\text { combination } \\
\text { with mm Calr1 }\end{array}$ \\
\hline & TATCAAGGGTGCCCGTCACCTTCAGC & 6 & + & 125163098 & 125163123 & $\begin{array}{l}\text { use in } \\
\text { combination } \\
\text { with Gapdh4 } \\
\text { Dekker }\end{array}$ \\
\hline & GGGCTTTTATAGCACGGTTATAAAGT & 6 & + & 125163774 & 125163799 & $\begin{array}{l}\text { use in } \\
\text { combination } \\
\text { with Gapdh3 } \\
\text { Dekker }\end{array}$ \\
\hline & GGAGGAGGGAAAAGGAGTGATT & 6 & + & 52212829 & 52212850 & $\begin{array}{l}\text { use in } \\
\text { combination } \\
\text { with mm } \\
\text { Hoxa13 }\end{array}$ \\
\hline
\end{tabular}




\begin{tabular}{|l|l|l|l|l|l|l|}
\hline & CAGGCATTATTGCTGAGAACG & 6 & - & 52253490 & 52253511 & $\begin{array}{l}\text { use in } \\
\text { combination } \\
\text { with mm } \\
\text { Hoxa7 }\end{array}$ \\
\hline & GGGTAATGGTGTCACTAACTGG & 13 & + & 23571284 & 23571305 & $\begin{array}{l}\text { use in } \\
\text { combination } \\
\text { with mm } \\
\text { Hist } 1 \mathrm{~h} 3 \mathrm{e} \text { or } \\
\mathrm{mm} \text { Hist } 1 \mathrm{~h} 4 \mathrm{i}\end{array}$ \\
\hline & GGGTTTGATGAGTTGGTGAAG & 13 & + & 23566541 & 23566561 & $\begin{array}{l}\text { use in } \\
\text { combination } \\
\text { with mm } \\
\text { Hist1h2ae }\end{array}$ \\
\hline & TTGGGCCAAAGCCTATATGA & 13 & + & 22043085 & 22043104 & $\begin{array}{l}\text { use in } \\
\text { combination } \\
\text { with mm } \\
\text { Hist1h2ae }\end{array}$ \\
\hline
\end{tabular}

Table 1: Primer sequences for quality control of human and mouse Hi-C libraries.

\section{Discussion}

\section{Modular design of Promoter Capture Hi-C}

Promoter Capture $\mathrm{Hi}-\mathrm{C}$ is designed to specifically enrich $\mathrm{Hi}-\mathrm{C}$ libraries for interactions involving promoters. These interactions comprise only a subset of ligation products present in a Hi-C library.

Capture $\mathrm{Hi}-\mathrm{C}$ can easily be modified to enrich $\mathrm{Hi}-\mathrm{C}$ libraries for any genomic region or regions of interest by changing the capture system. Capture regions can be continuous genomic segments ${ }^{44,45,46,48}$, enhancers that have been identified in PCHi-C ('Reverse Capture Hi-C'35), or DNase I hypersensitive sites ${ }^{49}$. The size of the capture system can be adjusted depending on the experimental scope. For example, Dryden et al. target 519 bait fragments in three gene deserts associated with breast cancer ${ }^{44}$. The capture system by Martin et al. targets both continuous genomic segments ('Region Capture': 211 genomic regions in total; 2,131 restriction fragments) and selected promoters (3,857 gene promoters) ${ }^{45}$.

SureSelect libraries are available in different size ranges: $1 \mathrm{~kb}$ to $499 \mathrm{~kb}(5,190-4,806), 500 \mathrm{~kb}$ to $2.9 \mathrm{Mb}(5,190-4,816)$, and $3 \mathrm{Mb}$ to $5.9 \mathrm{Mb}$ $(5,190-4,831)$. As each individual capture biotin-RNA is 120 nucleotides long, these capture systems accommodate a maximum of $4,158,24,166$ and 49,166 individual capture probes, respectively. This corresponds to 2,079, 12,083, and 24,583 targeted restriction fragments, respectively (note that the numbers for restriction fragments are lower bounds based on the assumption that two individual capture probes can be designed for every restriction fragment - in reality due to repetitive sequences this will not be the case for every restriction fragment (see also Figure 1B, C), resulting in a higher number of targetable restriction fragments for a constant number of available capture probes).

The protocol described here is based on the use of a restriction enzyme with a 6 bp recognition site to uncover long-range interactions. Using a restriction enzyme with a 4 bp recognition site for greater resolution of more proximal interactions is also possible ${ }^{40,49}$.

\section{Limitations of PCHi-C}

One inherent limitation of all chromosome conformation capture assays is that their resolution is determined by the restriction enzyme used for the library generation. Interactions that occur between DNA elements located on the same restriction fragment are invisible to 'C-type' assays. Further, in $\mathrm{PCHi}-\mathrm{C}$, in some cases more than one transcription start site can be located on the same promoter-containing restriction fragment, and PIRs in some cases harbor both active and repressive histone marks, making it difficult to pinpoint which regulatory elements mediate the interactions, and to predict the regulatory output of promoter interactions. Using restriction enzymes with 4 bp recognition sites mitigates this issue but comes at the expense of vastly increased $\mathrm{Hi}-\mathrm{C}$ library complexity ( $\mathrm{Hi}-\mathrm{C}$ libraries generated with 4 bp recognition site restriction enzymes are at least 100 times more complex than Hi-C libraries generated with 6 bp recognition site restriction enzymes), and the associated costs for next generation sequencing.

Another limitation is that the current $\mathrm{PCHi}-\mathrm{C}$ protocol requires millions of cells as starting material, precluding the analysis of promoter interactions in rare cell types. A modified version of $\mathrm{PCHi}-\mathrm{C}$ to enable the interrogation of promoter contacts in cell populations with 10,000 to 100,000 cells (for example cells during early embryonic development or hematopoietic stem cells) would therefore be a valuable addition to the Capture Hi-C toolbox.

Finally, like all methods that rely on formaldehyde fixation, $\mathrm{PCHi}-\mathrm{C}$ only records interactions that are 'frozen' at the time point of fixation. Thus, to study the kinetics and dynamics of promoter interactions, methods such as super-resolution live cell microscopy are required alongside PCHi-C.

\section{Methods to dissect spatial chromosome organization at high resolution}

The vast complexity of chromosomal interaction libraries prohibits the reliable identification of interaction products between two specific restriction fragments with statistical significance. To circumvent this problem, sequence capture has been used to enrich either Hi- $\mathrm{C}^{33,34,40,44}$ or $3 \mathrm{C}^{50,51}$ libraries for specific interactions. The major advantage of using $\mathrm{Hi}-\mathrm{C}$ libraries over $3 \mathrm{C}$ libraries for the enrichment step is that $\mathrm{Hi}-\mathrm{C}$, unlike $3 \mathrm{C}$, includes an enrichment step for genuine ligation products. As a consequence, the percentage of valid reads in PCHi-C libraries is 
approximately 10 -fold higher than in Capture-C libraries ${ }^{50}$, which contained around $5-8 \%$ valid reads after HiCUP filtering. Sahlen et al. have directly compared Capture- $\mathrm{C}$ to HiCap, which like $\mathrm{PCHi}-\mathrm{C}$ uses $\mathrm{Hi}-\mathrm{C}$ libraries for capture enrichment, in contrast to Capture- $\mathrm{C}$ which uses $3 \mathrm{C}$ libraries. Consistent with our findings, they found that Capture-C libraries are mainly composed of un-ligated fragments ${ }^{40}$. In addition, HiCap libraries had a higher complexity than Capture-C libraries ${ }^{40}$

A variant of Capture-C, called next-generation Capture- $\mathrm{C}^{52}$ (NG Capture-C) uses one oligo per restriction fragment end, as previously established in $\mathrm{PCHi}-\mathrm{C}^{33,34}$, instead of overlapping probes used in the original Capture-C protocol ${ }^{50}$. This increases the percentage of valid reads compared to Capture-C modestly, but NG Capture-C employs two sequential rounds of capture enrichment, and a relatively high number of PCR cycles (20 to 24 cycles in total, compared to 11 cycles typically for $\mathrm{PCHi}-\mathrm{C}$ ), which inevitably results in higher numbers of sequence duplicates and lower library complexity. In trial experiments during the optimization of $\mathrm{PCHi}-\mathrm{C}$, we found that the percentage of unique (i.e., not duplicated) read pairs was only around $15 \%$ when we used 19 PCR cycles (13 cycles pre-capture +6 cycles post-capture; data not shown), however optimization to a lower number of PCR cycles, typically yields $75-90 \%$ unique read pairs. Thus, reducing the number of PCR cycles substantially increases the amount of informative sequence data.

A recent method combines ChIP with $\mathrm{Hi}-\mathrm{C}$ to focus on chromosomal interactions mediated by a specific protein of interest $\left(\mathrm{HiCh} / \mathrm{P}^{53}\right)$. Compared to ChIA-PET ${ }^{54}$, which is based on a similar rationale, HiChIP data contains a higher number of informative sequence reads, allowing for higher-confidence interaction calling ${ }^{53}$. It will be very interesting to directly compare the corresponding HiChIP and Capture Hi-C data sets once they become available (for example HiChIP using an antibody against the cohesin unit Smc1 $\mathrm{a}^{53}$ with Capture Hi-C for all Smc1a bound restriction fragments) side by side. One inherent difference between these two approaches is that Capture Hi-C does not rely on chromatin immunoprecipitation, and therefore is capable of interrogating chromosomal interactions irrespective of protein occupancy. This enables comparison of 3D genome organization in the presence or absence of specific factor binding, as has been used to identify PRC1 as a key regulator of mouse ESC spatial genome architecture ${ }^{7}$.

\section{PCHi-C and GWAS}

Genome-wide association studies (GWAS) have revealed that greater than 95\% of disease-associated sequence variants are located in noncoding regions of the genome, often at great distances to protein-coding genes ${ }^{55}$. GWAS variants are often found in close proximity to DNase I hypersensitive sites, which is a hallmark of sequences with potential regulatory activity. $\mathrm{PCHi}-\mathrm{C}$ and Capture $\mathrm{Hi}-\mathrm{C}$ have been used extensively to link promoters to GWAS risk loci implicated in breast cancer ${ }^{44}$, colorectal cancer ${ }^{48}$, and autoimmune disease ${ }^{35,45,46}$. A PCHi-C study on 17 different human hematopoietic cell types found SNPs associated with autoimmune disease were enriched in PIRs in lymphoid cells, whereas sequence variants associated with platelet and red blood cell specific traits were predominantly found in the macrophages and erythroblasts, respectively ${ }^{35,56}$. Thus, tissue-type specific promoter interactomes uncovered by $\mathrm{PCHi}-\mathrm{C}$ may help to understand the function of non-coding disease-associated sequence variants and identify new potential disease genes for therapeutic intervention.

\section{Characteristics of promoter-interacting regions}

Several lines of evidence link promoter interactomes to gene expression control. First, several PCHi-C studies have demonstrated that genomic regions interacting with promoters of (highly) expressed genes are enriched in marks associated with enhancer activity, such as $\mathrm{H} 3 \mathrm{~K} 27$ acetylation and p300 binding ${ }^{33,34,37}$. We found a positive correlation between gene expression level and the number of interacting enhancers, suggesting that additive effects of enhancers result in increased gene expression levels ${ }^{34,35}$. Second, naturally occurring expression quantitative trait loci (eQTLs) are enriched in PIRs that are connected to the same genes whose expression is affected by the eQTLs ${ }^{35}$. Third, by integrating TRIP $^{57}$ and PCHi-C data, Cairns et al. found that TRIP reporter genes mapping to PIRs in mouse ESCs show stronger reporter gene expression than reporter genes at integration sites in non-promoter-interacting regions ${ }^{58}$, indicating that PIRs possess transcriptional regulatory activity. Together, these findings suggest that promoter interactomes uncovered by $\mathrm{PCHi}-\mathrm{C}$ in various mouse and human cell types include key regulatory modules for gene expression control.

It is worth noting that enhancers represent only a small fraction $(\sim 20 \%)$ of all PIRs uncovered by PCHi-C ${ }^{33,34}$. Other PIRs could have structural or topological roles rather than direct transcriptional regulatory functions. However, there is also evidence that PCHi-C may uncover DNA elements with regulatory function that do not harbor classical enhancer marks. In a human lymphoid cell line, the BRD7 promoter was found to interact with a region devoid of enhancer marks that was shown to possess enhancer activity in reporter gene assays ${ }^{33}$. Regulatory elements with similar characteristics may be more abundant than currently appreciated. For example, a CRISPR-based screen for regulatory DNA elements identified unmarked regulatory elements (UREs) that control gene expression but are devoid of enhancer marks ${ }^{59}$.

In other cases, PIRs have been shown to harbor chromatin marks associated with transcriptional repression. PIRs and interacting promoters bound by PRC1 in mouse ESCs were engaged in an extensive spatial network of repressed genes bearing the repressive mark $\mathrm{H}_{3 \mathrm{~K}} 27 \mathrm{me} 3^{7}$. In human lymphoblastoid cells, a distant element interacting with the BCL6 promoter repressed transgene reporter gene expression ${ }^{33}$, suggesting that it may function to repress $B C L 6$ transcription in its native context.

PIRs enriched for occupancy of the chromatin insulator protein CTCF in human ESCs and NECs ${ }^{37}$ may represent yet another class of PIRs. Collectively, these results suggest that PIRs harbor a collection of gene regulatory activities yet to be functionally characterized.

\section{Disclosures}

Authors have nothing to disclose.

\section{Acknowledgements}

We thank Valeriya Malysheva for critical reading of the manuscript and expert help with Figure 1. This work was supported by the Medical Research Council, UK (MR/L007150/1) and the UK Biotechnology and Biological Sciences Research Council, UK (BB/J004480/1). 


\section{References}

1. Osborne, C. S. et al. Active genes dynamically colocalize to shared sites of ongoing transcription. Nature Genetics . 36, 1065-1071 (2004).

2. Schoenfelder, S. et al. Preferential associations between co-regulated genes reveal a transcriptional interactome in erythroid cells. Nature Genetics . 42, 53-61 (2010).

3. de Wit, E. et al. The pluripotent genome in three dimensions is shaped around pluripotency factors. Nature. 501, 227-231 (2013).

4. Bantignies, F. et al. Polycomb-dependent regulatory contacts between distant Hox loci in Drosophila. Cell. 144, 214-226 (2011).

5. Engreitz, J. M. et al. The Xist IncRNA exploits three-dimensional genome architecture to spread across the X chromosome. Science. 341, 1237973 (2013).

6. Denholtz, M. et al. Long-range chromatin contacts in embryonic stem cells reveal a role for pluripotency factors and polycomb proteins in genome organization. Cell Stem Cell. 13, 602-616 (2013).

7. Schoenfelder, S. et al. Polycomb repressive complex PRC1 spatially constrains the mouse embryonic stem cell genome. Nature Genetics . 47, 1179-1186 (2015).

8. Kundu, S. et al. Polycomb Repressive Complex 1 generates discrete compacted domains that change during differentiation. Molecular Cell 65, $432-446$ e435 (2017).

9. Skok, J.A., Gisler, R., Novatchkova, M., Farmer, D., de Laat, W., Busslinger, M. Reversible contraction by looping of the Tcra and Tcrb loci in rearranging thymocytes. Nature Immunology . 8, 378-387 (2007).

10. Zhang, Y. et al. Spatial organization of the mouse genome and its role in recurrent chromosomal translocations. Cell. 148, 908-921 (2012).

11. Aymard, F. et al. Genome-wide mapping of long-range contacts unveils clustering of DNA double-strand breaks at damaged active genes. Nature Structural \& Molecular Biology . 24, 353-361 (2017).

12. Ryba, T. et al. Evolutionarily conserved replication timing profiles predict long-range chromatin interactions and distinguish closely related cell types. Genome Research. 20, 761-770 (2010).

13. Pope, B. D. et al. Topologically associating domains are stable units of replication-timing regulation. Nature. 515, 402-405 (2014).

14. Chandra, T. et al. Global reorganization of the nuclear landscape in senescent cells. Cell Reports . 10, 471-483 (2015).

15. Carter, D., Chakalova, L., Osborne, C. S., Dai, Y. F., Fraser, P. Long-range chromatin regulatory interactions in vivo. Nature Genetics . 32, 623-626 (2002).

16. Tolhuis, B., Palstra, R. J., Splinter, E., Grosveld, F., de Laat, W. Looping and interaction between hypersensitive sites in the active beta-globin locus. Molecular Cell . 10, 1453-1465 (2002)

17. Amano, T., Sagai, T., Tanabe, H., Mizushina, Y., Nakazawa, H., Shiroishi, T. Chromosomal dynamics at the Shh locus: limb bud-specific differential regulation of competence and active transcription. Developmental Cell. 16, 47-57 (2009).

18. Zuniga, A. et al. Mouse limb deformity mutations disrupt a global control region within the large regulatory landscape required for Gremlin expression. Genes \& Development . 18, 1553-1564 (2004).

19. Sagai, T., Hosoya, M., Mizushina, Y., Tamura, M., Shiroishi, T. Elimination of a long-range cis-regulatory module causes complete loss of limb-specific Shh expression and truncation of the mouse limb. Development. 132, 797-803 (2005).

20. D'Haene, B. et al. Disease-causing $7.4 \mathrm{~kb}$ cis-regulatory deletion disrupting conserved non-coding sequences and their interaction with the FOXL2 promotor: implications for mutation screening. PLoS Genet. 5, e1000522 (2009).

21. Sur, I. K. et al. Mice lacking a Myc enhancer that includes human SNP rs6983267 are resistant to intestinal tumors. Science. 338, 1360-1363 (2012).

22. Herranz, D. et al. A NOTCH1-driven MYC enhancer promotes T cell development, transformation and acute lymphoblastic leukemia. Nature Medicine . 20, 1130-1137 (2014).

23. Deng, W. et al. Controlling long-range genomic interactions at a native locus by targeted tethering of a looping factor. Cell. 149, 1233-1244 (2012).

24. Groschel, S. et al. A single oncogenic enhancer rearrangement causes concomitant EVI1 and GATA2 deregulation in leukemia. Cell. 157, 369-381 (2014).

25. Lupianez, D. G. et al. Disruptions of topological chromatin domains cause pathogenic rewiring of gene-enhancer interactions. Cell. 161, 1012-1025 (2015).

26. Franke, M. et al. Formation of new chromatin domains determines pathogenicity of genomic duplications. Nature . 538, 265-269 (2016).

27. Dekker, J., Rippe, K., Dekker, M., Kleckner, N. Capturing chromosome conformation. Science. 295, 1306-1311 (2002).

28. Simonis, M. et al. Nuclear organization of active and inactive chromatin domains uncovered by chromosome conformation capture-on-chip (4C). Nature Genetics . 38, 1348-1354 (2006).

29. Zhao, Z. et al. Circular chromosome conformation capture (4C) uncovers extensive networks of epigenetically regulated intra- and interchromosomal interactions. Nature Genetics . 38, 1341-1347 (2006).

30. Dostie, J. et al. Chromosome Conformation Capture Carbon Copy (5C): A massively parallel solution for mapping interactions between genomic elements. Genome Research . 16, 1299-1309 (2006).

31. Lieberman-Aiden, E. et al. Comprehensive mapping of long-range interactions reveals folding principles of the human genome. Science. 326, 289-293 (2009).

32. Belton, J.M., McCord, R.P., Gibcus, J.H., Naumova, N., Zhan, Y., Dekker, J. Hi-C: a comprehensive technique to capture the conformation of genomes. Methods. 58, 268-276 (2012).

33. Mifsud, B. et al. Mapping long-range promoter contacts in human cells with high-resolution capture Hi-C. Nature Genetics. 47, 598-606 (2015).

34. Schoenfelder, S. et al. The pluripotent regulatory circuitry connecting promoters to their long-range interacting elements. Genome Res. $\mathbf{2 5}$, 582-597 (2015).

35. Javierre, B. M. et al. Lineage-specific genome architecture links enhancers and non-coding disease variants to target gene promoters. Cell. 167, 1369-1384 e1319 (2016).

36. Wilson, N. K. et al. Integrated genome-scale analysis of the transcriptional regulatory landscape in a blood stem/progenitor cell model. Blood. 127, e12-23 (2016). 
37. Freire-Pritchett, P. et al. Global reorganisation of cis-regulatory units upon lineage commitment of human embryonic stem cells. Elife. 6 (2017).

38. Rubin, A. J. et al. Lineage-specific dynamic and pre-established enhancer-promoter contacts cooperate in terminal differentiation. Nature Genetics . 49, 1522-1528 (2017).

39. Siersbaek, R. et al. Dynamic rewiring of promoter-anchored chromatin loops during adipocyte differentiation. Molecular Cell . 66, 420-435 e425 (2017).

40. Sahlen, P. et al. Genome-wide mapping of promoter-anchored interactions with close to single-enhancer resolution. Genome Biology. 16, 156 (2015).

41. Nagano, T. et al. Single-cell Hi-C reveals cell-to-cell variability in chromosome structure. Nature. 502, 59-64 (2013).

42. Nagano, T., Varnai, C., Schoenfelder, S., Javierre, B.M., Wingett, S.W., Fraser, P. Comparison of Hi-C results using in-solution versus innucleus ligation. Genome Biology. 16, 175 (2015).

43. Wingett, S. et al. HiCUP: pipeline for mapping and processing Hi-C data. F1000 Res. 4, 1310 (2015).

44. Dryden, N. H. et al. Unbiased analysis of potential targets of breast cancer susceptibility loci by Capture Hi-C. Genome Research . 24, 1854-1868 (2014).

45. Martin, P. et al. Capture Hi-C reveals novel candidate genes and complex long-range interactions with related autoimmune risk loci. Nature Communications. 6, 10069 (2015).

46. McGovern, A. et al. Capture Hi-C identifies a novel causal gene, IL20RA, in the pan-autoimmune genetic susceptibility region 6q23. Genome Biol.ogy 17, 212 (2016)

47. Hodge, D. et al. A global role for EKLF in definitive and primitive erythropoiesis. Blood. 107, 3359-3370 (2006).

48. Jager, R. et al. Capture Hi-C identifies the chromatin interactome of colorectal cancer risk loci. Nature Communications. 6, 6178 (2015).

49. Joshi, O. et al. Dynamic reorganization of extremely long-range promoter-promoter Interactions between two states of pluripotency. Cell Stem Cell . 17, 748-757 (2015).

50. Hughes, J. R. et al. Analysis of hundreds of cis-regulatory landscapes at high resolution in a single, high-throughput experiment. Nature Genetics . 46, 205-212 (2014).

51. Kolovos, P. et al. Targeted Chromatin Capture (T2C): A novel high-resolution high-throughput method to detect genomic interactions and regulatory elements. Epigenetics Chromatin. 7, 10 (2014).

52. Davies, J. O. et al. Multiplexed analysis of chromosome conformation at vastly improved sensitivity. Nature Methods . 13, 74-80 (2016).

53. Mumbach, M. R. et al. HiChIP: efficient and sensitive analysis of protein-directed genome architecture. Nature Methods . 13, 919-922 (2016).

54. Fullwood, M. J. et al. An oestrogen-receptor-alpha-bound human chromatin interactome. Nature. 462, 58-64 (2009).

55. Maurano, M. T. et al. Systematic localization of common disease-associated variation in regulatory DNA. Science. 337, 1190-1195 (2012).

56. Petersen, R. et al. Platelet function is modified by common sequence variation in megakaryocyte super enhancers. Nat. Commun. 8, 16058 (2017).

57. Akhtar, W. et al. Chromatin position effects assayed by thousands of reporters integrated in parallel. Cell. 154, 914-927 (2013).

58. Cairns, J. et al. CHiCAGO: Robust detection of DNA looping interactions in Capture Hi-C data. Genome Biology. 17, 127 (2016).

59. Rajagopal, N. et al. High-throughput mapping of regulatory DNA. Nature Biotechnology. 34, 167-174 (2016). 